\title{
SyntheticBiology \\ Reverse Engineering of an Aspirin-Responsive Transcriptional Regulator in Escherichia coli
}

\author{
Lummy Maria Oliveira Monteiro, ${ }^{\dagger}$ Letícia Magalhães Arruda, ${ }^{\dagger}$ Ananda Sanches-Medeiros, ${ }^{\dagger}$
} Leonardo Martins-Santana, ${ }^{\dagger}$ Luana de Fátima Alves, ${ }^{\ddagger}$ Lucas Defelipe, ${ }^{\S, \| ®}$ Adrian Gustavo Turjanski, ${ }^{\S}, \|$

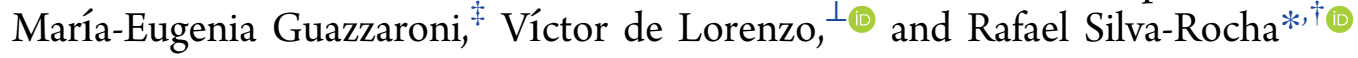

${ }^{\dagger}$ Cell and Molecular Biology Department, FMRP - University of São Paulo, Ribeirão Preto, São Paulo 14049-900, Brazil

${ }^{\ddagger}$ Biology Department, FFCLRP - University of São Paulo, Ribeirão Preto, São Paulo 14040-901, Brazil

${ }^{\S}$ Departamento de Química Biológica, Facultad de Ciencias Exactas y Naturales, Universidad de Buenos Aires, Buenos Aires 1428, Argentina

"IQUIBICEN/UBA-CONICET, Facultad de Ciencias Exactas y Naturales, Universidad de Buenos Aires, Buenos Aires 1428, Argentina

${ }^{\perp}$ Systems Biology Program, National Center of Biotechnology - CSIC, Madrid 28049, Spain

\section{Supporting Information}

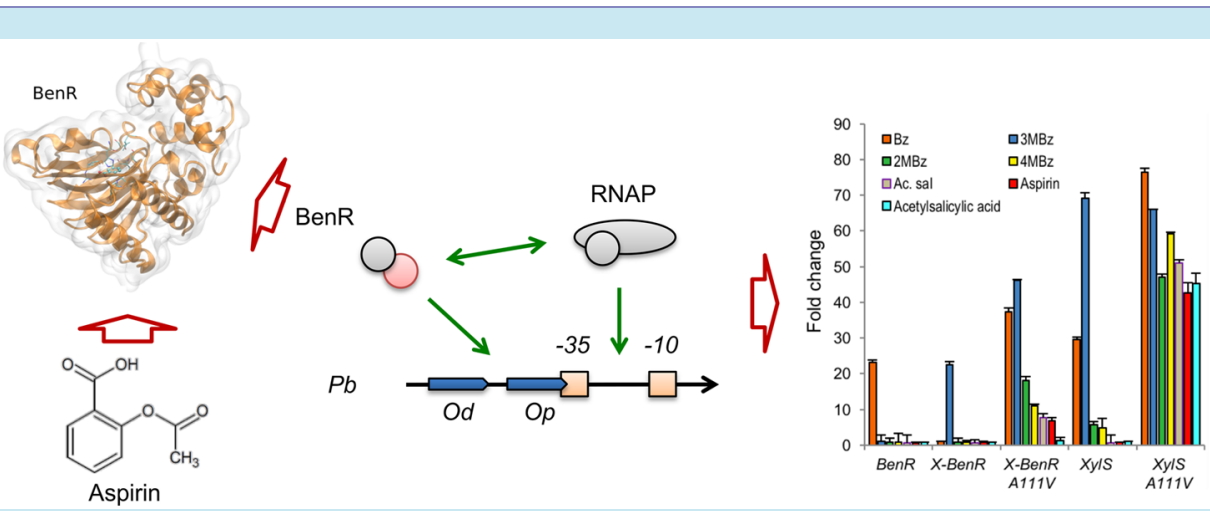

ABSTRACT: Bacterial transcription factors (TFs) are key devices for the engineering of complex circuits in many biotechnological applications, yet there are few well-characterized inducer-responsive TFs that could be used in the context of an animal or human host. We have deciphered the inducer recognition mechanism of two AraC/XylS regulators from Pseudomonas putida (BenR and XylS) for creating a novel expression system responsive to acetyl salicylate (i.e., aspirin). Using protein homology modeling and molecular docking with the cognate inducer benzoate and a suite of chemical analogues, we identified the conserved binding pocket of BenR and XylS. By means of site-directed mutagenesis, we identified a single amino acid position required for efficient inducer recognition and transcriptional activation. Whereas this modification in BenR abolishes protein activity, in XylS, it increases the response to several inducers, including acetyl salicylic acid, to levels close to those achieved by the canonical inducer. Moreover, by constructing chimeric proteins with swapped N-terminal domains, we created novel regulators with mixed promoter and inducer recognition profiles. As a result, a collection of engineered TFs was generated with an enhanced response to benzoate, 3-methylbenzoate, 2-methylbenzoate, 4-methylbenzoate, salicylic acid, aspirin, and acetylsalicylic acid molecules for eliciting gene expression in E. coli.

KEYWORDS: transcriptional regulation, protein engineering, homology modeling, gene regulatory network, reverse engineering, bacterial expression system

$\mathrm{T}$ ranscriptional regulation plays a central role in the adaptation of cells to changing environmental conditions. In bacteria, this step is mainly regulated by the interaction of RNA polymerase (RNAP) with the promoter region through the use of many sigma factors and by a large number of transcription factors (TFs) that can promote or block RNAP binding or further steps in transcription. ${ }^{1}$ With the growing interest in the engineering of living cells for novel biotechnological and biomedical applications, a special focus has emerged in understanding gene regulation at the molecular level. ${ }^{1-4}$ In this context, many different classes of TFs have been extensively characterized in the molecular detail from bacteria to mammals, and this knowledge has allowed a number of engineering projects, where natural systems can be

Received: April 29, 2019

Published: July 30, 2019 


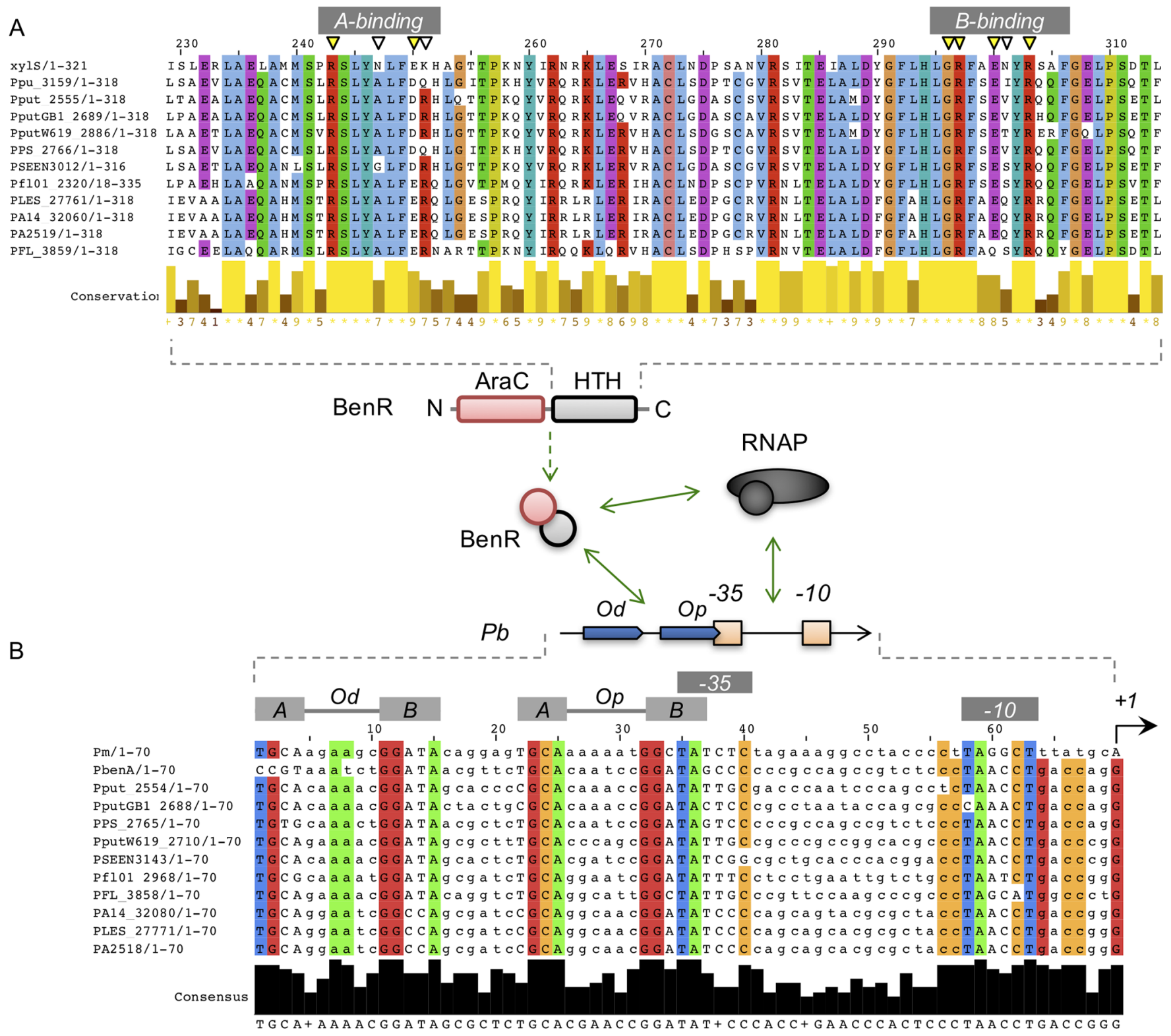

Figure 1. Analysis of BenR homologues and target promoters in Pseudomonas. (A) Analysis of protein conservation between XylS from Pseudomonas putida mt-2 and BenR homologues from strains of P. putida (Ppu 3159, Pput 2555, PputGB1 2689, PputW619 2886, PPS 2765), P. entomophila (PSEEN3143), P. fluorescens (Pfl01_2968, PFL_3858), and P. aeruginosa (PA14_32080, PLES_27771, PA2518). PbanA in the second line indicates the promoter from P. putida KT2440 (Ppu 3159). Only the region relative to the HTH domain is shown. Critical aa's for DNA recognition (labeled as A-binding and B-binding) are marked with inverted triangles, with conserved regions colored in yellow. In the middle, the schematic representation of the BenR interaction with the RNAP and the $\sigma$ factor (necessary for the correct initiation of transcription) and the target promoter shows the two binding sites (Od and $O p$ ) and the $-35 /-10$ boxes at $P b$ and $P m$. (B) Promoter alignment for Pm from $P$. putida mt-2 and for $\mathrm{Pb}$ from several Pseudomonas strains. The two conserved boxes (A and B) from $\mathrm{Od}$ and $\mathrm{Op}$ binding sites are highlighted.

repurposed to display novel behaviors. ${ }^{1,5-9}$ Attempts in this direction are very diverse, and examples include the construction of mutated variants of natural TFs with enhanced or modified performance, ${ }^{10-15}$ the recombination of protein domains to create TFs with completely altered specificity or dynamical behavior, ${ }^{16,17}$ and the mining of novel regulators from genomes or metagenomes. ${ }^{18,19}$ Additionally, the revolution provided by the CRISPR/Cas9 system has also impacted the field of gene regulation, as this system has been repurposed to construct fully synthetic expression systems based on RNA/ DNA interaction. ${ }^{20-22}$

Despite the progress in the engineering of novel expression systems, a critical bottleneck relies on the selection of suitable signal-recognition modules related to the application of interest. In other words, whereas many different TFs are well-characterized as responsive to small molecules (sugars, ions, aromatics, etc.), many times, the application at stake requires systems responsive to unusual compounds. ${ }^{23}$ Therefore, the construction of TF variants with enhanced responsiveness to non-natural ligands has become more appealing. Approaches to accomplish this task range from the use of laborious random mutagenesis followed by selection ${ }^{11,12}$ to the use of computational analysis to guide rational design. ${ }^{24}$ Here we focused on the engineering of novel expression systems responsive to commercially available drugs suitable to in vivo administration to a mammalian animal. Our 


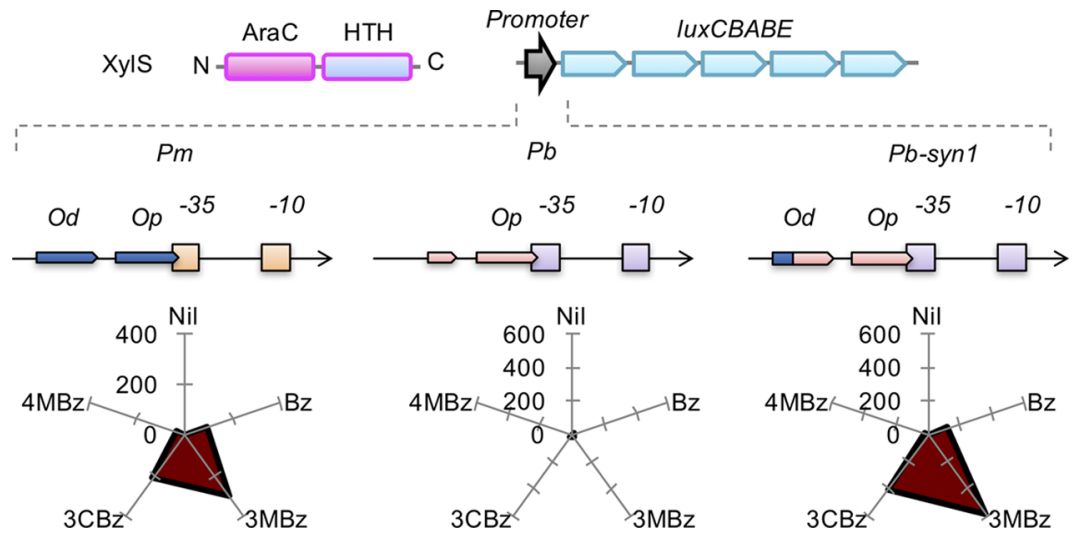

Figure 2. Recognition of $P m$ and $P b$ by XylS. For the analysis, E. coli DH5 $\alpha$ strain was transformed with pSEVA438 (harboring a functional XylS expressed with its native promoter ${ }^{33}$ ) and pSEVA226 (a reporter vector with the luxCDABE operon ${ }^{33}$ ) harboring $P m, P b$, or $P b$-syn1, a variant of $\mathrm{Pb}$ endowed with the A box of $\mathrm{Od}$ from $\mathrm{Pm} .{ }^{27}$ All strains were grown on minimal media to the midexponential phase and then exposed for $3 \mathrm{~h}$ to $100 \mu \mathrm{M}$ benzoate $(\mathrm{Bz}), 3$-methylbenzoate $(3 \mathrm{MBz})$, 3-chlorobenzoate $(3 \mathrm{CBz})$, or 4-methylbenzoate $(4 \mathrm{MBz})$. The graphs represent the fold change of promoter activity relative to the noninduced condition.

particular interest was focused on acetylsalicylic acid (ASA or aspirin), a longstanding, safe and widely used drug. This compound has been applied in synthetic regulatory circuits to deliver lytic proteins to tumors in vivo, representing a promising field for the development of tumor-targeting circuits for clinical applications. ${ }^{25}$ As a starting point, we sought to investigate the molecular mechanisms of signal recognition by two homologous regulators of Pseudomonas putida, namely, BenR and XylS. These two TFs are members of the AraC/XylS family of transcriptional activators ${ }^{26-28}$ that recognize different aromatic compounds with structural similarities to ASA. Yet, whereas both regulators share $\sim 60 \%$ amino acid (aa) identity, BenR is responsive to only benzoate, ${ }^{27}$ whereas XylS can recognize a large number of substituted variants. ${ }^{29}$ Additionally, some crosstalk between these two regulators and their target promoters has been characterized, as XylS can recognize only its target promoter $\mathrm{Pm}$, whereas BenR can efficiently activate its natural target $\mathrm{Pb}$ as well as $\mathrm{Pm} .^{27}$

In this study, we have investigated the molecular mechanisms of signal recognition by these two regulators using computational tools and in vivo validation. By constructing a model for the ligand-binding domain of BenR and performing molecular docking with benzoate and a collection of analogues, we identified a potential binding pocket strongly conserved between these two TFs. Thereby, we used site-directed mutagenesis and the construction of chimeric proteins to validate the identified binding pocket of the protein. Finally, we demonstrated how a single aa position plays a critical and opposite role in the activity of both proteins. Some changes in this position in BenR resulted in the complete loss of protein activity, whereas the same in XylS triggered an enhanced response to benzoate analogues, including ASA. The results presented here thus provide insights into not only the mechanism of signal recognition by members of the AraC/XylS family but also the engineering of a regulatory device responsive to aspirin.

\section{RESULTS}

Analysis of Conserved Elements in BenR and XyIS Close Homologues and Target Promoters. To investigate the molecular mechanisms accounting for the functional differences between BenR and XylS, we analyzed the close homologues of these proteins present in the genomes of some species of Pseudomonas. As represented schematically in Figure 1 , these proteins are TFs formed by two domains, the $\mathrm{N}$ terminal (AraC domain), which is required for ligand recognition, ${ }^{30}$ and the $\mathrm{C}$-terminal domain composed of two helix-turn-helix $(\mathrm{HTH})$ regions required for the recognition of the distal and proximal operators $(O d$ and $O p)$ upstream of the target promoters. ${ }^{27,31}$ It is proposed that two monomers of XylS are required for the activation of the $P m$ promoter, each binding to an operator region and contacting an $\mathrm{A}$ and $\mathrm{B}$ box conserved within this region. A previous study ${ }^{32}$ used alanine scanning mutagenesis to identify four residues in XylS required for the recognition of the A boxes (Arg242, Asn246, Glu249, and Lys250) and five required for the interaction with boxes $B$ (G295, Arg296, Asp299, Asn300 and Arg302). As can be observed in the protein alignment between BenR and XylS homologues, most of these positions are well conserved in the proteins analyzed, with the exception of residues Asn246, Lys250, and Asn 300 (Figure 1A). It is surprising to notice that whereas the change of Asn to Ala at position 246 in XylS reduced the capability of this protein to activate $P m$ by half, $\mathrm{Ala}$ is found to be well-conserved in most BenR proteins analyzed. This indicates that BenR homologues might be less stringent in the interaction at the A box of the target promoter. $^{27}$ In the same direction of this hypothesis, the analysis of $\mathrm{Pm}$ and $\mathrm{Pb}$ promoters from several Pseudomonas strains reveals that most features (A and B boxes, $-35 / 10$ region) are well conserved, except for the $\mathrm{A}$ box of $\mathrm{Pb}$ (the target of the BenR studied here) from Pseudomonas putida KT2440 (Figure 1B). In this sense, to check the effect of the A box in the interaction between XylS and $P m$ and $P b$ promoters, we assayed the promoter activity using a lux reporter system. We used a wild-type $x y l S$ gene expressed from a pSEVA vector $^{33}$ and $P m, P b$, and $P b$-syn 1 (a $P b$ variant with the recomposed A box of the $O d$ region $^{27}$ ). Using this system, we observed that whereas XylS could recognize $P m$ very efficiently, it was not able to induce $\mathrm{Pb}$ activity in response to the inducers tested (Figure 2). However, when a version of $\mathrm{Pb}$ with the reconstituted A box ( $P b$-syn 1$)$ was used, a strong induction of promoter activity was observed in response to the inducers used (Figure 2). ${ }^{27}$ Taken together, these results reinforce the notion that whereas XylS has a critical requirement for complete $\mathrm{A}$ and $\mathrm{B}$ boxes at the $\mathrm{Od}$ and $\mathrm{Op}$ regions, BenR is less stringent for promoter recognition. 


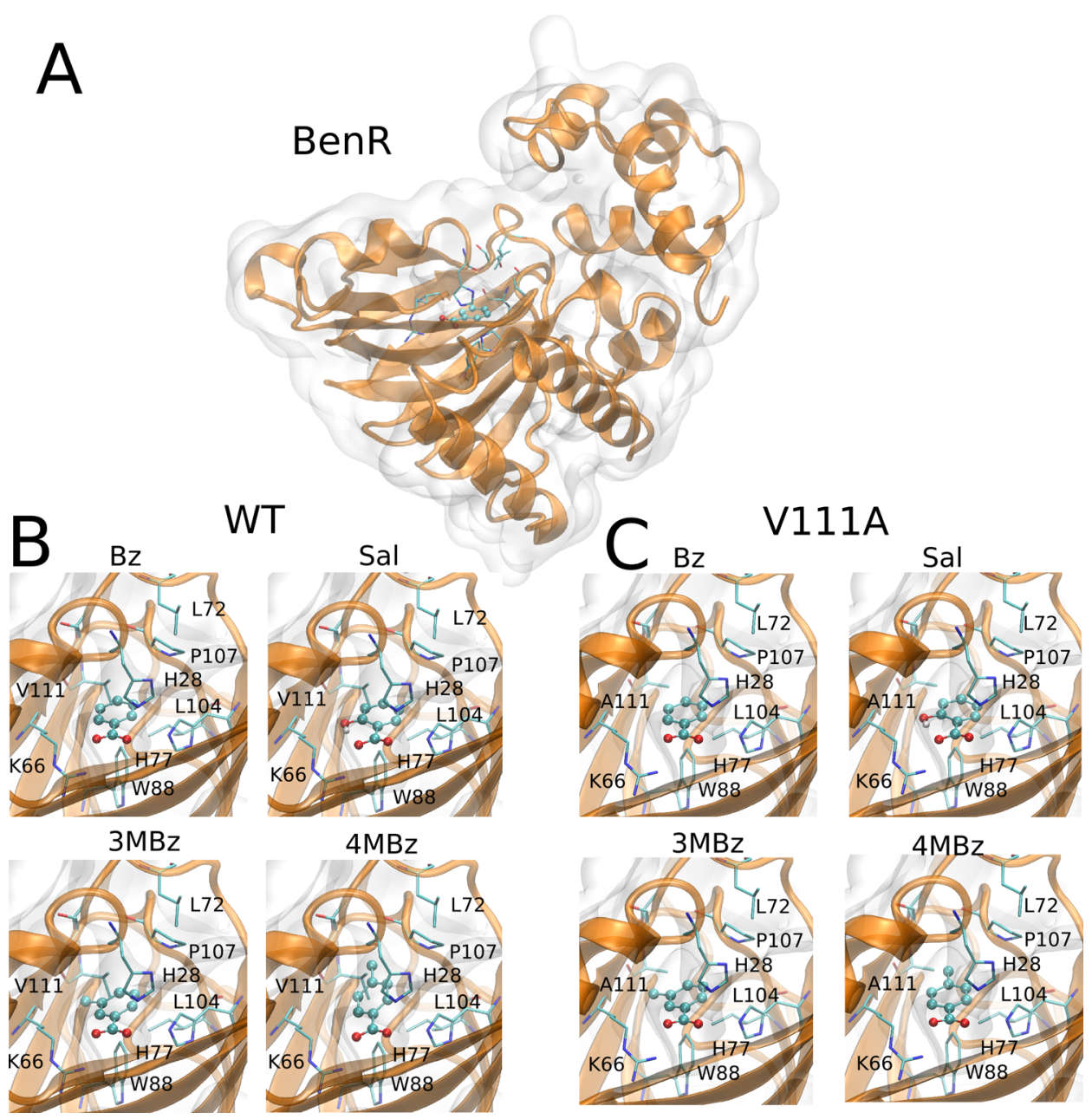

Figure 3. Mapping ligand binding sites in BenR by protein structure prediction and molecular docking. (A) Homology model of wild-type BenR showing the putative binding site of the ligands. (B) Docking of benzoate (Bz), 3-methylbenzoate (3MBz), 4-methylbenzoate (4MBz), and salicylate (Sal) at the wild-type BenR protein, highlighting the critical aa participating in the putative binding site. (C) Docking of BenR-V111A variant showing the putative binding site, as in panel B.

\footnotetext{
Single Amino Acid Position Is Critical for Aromatic Recognition in BenR and XylS. After tracing critical differences in the DNA recognition requirements between BenR and XylS, we decided to investigate aa differences that could explain the divergence in the ligand selectivity between these two TFs. As presented before, BenR has a very narrow inducer selectivity because this TF can only respond to benzoate as an inducer under natural conditions. However, XylS can be activated by a diverse collection of aromatic inducers, such as benzoate and methylated or chlorinated benzoate analogues. ${ }^{29}$ To gain insight into the molecular mechanisms responsible for these differences, we constructed a 3D protein model for the $\mathrm{N}$-terminal region of BenR using homology modeling. The resulting model was subjected to molecular docking using benzoate, 3-methylbenzoate $(3 \mathrm{MBz})$, 4-methylbenzoate $(4 \mathrm{MBz})$, and salicylate (Sal). Using this approach, we obtained a protein structural model (Figure 3A) and identified a potential cavity on the protein surface that accommodates a benzoate molecule (Figure 3B). Additionally, our results suggest that the identified binding pocket binds with less affinity for the benzoate analogues, indicating that the inducer selectivity could be based on size exclusion. By analyzing the model and the predicted binding pocket, we could identify eight aa's (His 28 , Arg 66, Leu 72, His 77, Trp
}

88, Leu 104, Pro 107, and Val 111) that contributed to the surface of the cavity (Figure 3B,C). We then compared these aa's between BenR and XylS, hypothesizing that a change in some of these aa's could explain the difference in ligand specificity between these two regulators. To our surprise, six out eight aa's from the predicted binding pocket were conserved between the two proteins. The differences were at positions 28 and 111, representing histidine (28) and valine (111) in BenR and tyrosine (28) and alanine (111) in XylS. Because alanine has a shorter side chain, we hypothesized that this could lead to a bigger binding pocket in XylS that could better accommodate the methylated or chlorinated benzoate analogues (Figure 3C and Table S3).

The difference in binding energy suggests that mutation of Val111 to Ala increases the affinity of $3 \mathrm{MBz}$ (Table S3). To investigate this possibility, we constructed point mutations in $b e n R$ and $x y l S$ at aa positions 111 and 110 , as we noticed that this last position, while not involved in the binding pocket, was also not conserved between the two regulators (Figure 4A). In addition to the point mutations, we constructed a chimaera between the $\mathrm{N}$-terminal part of XylS and the C-terminal part of BenR and also subjected this TF to mutagenesis. All assays were performed using the cognate promoter for each TF (i.e., $\mathrm{Pb}$ for BenR and $\mathrm{Pm}$ for XylS) controlling a green fluorescent 
A
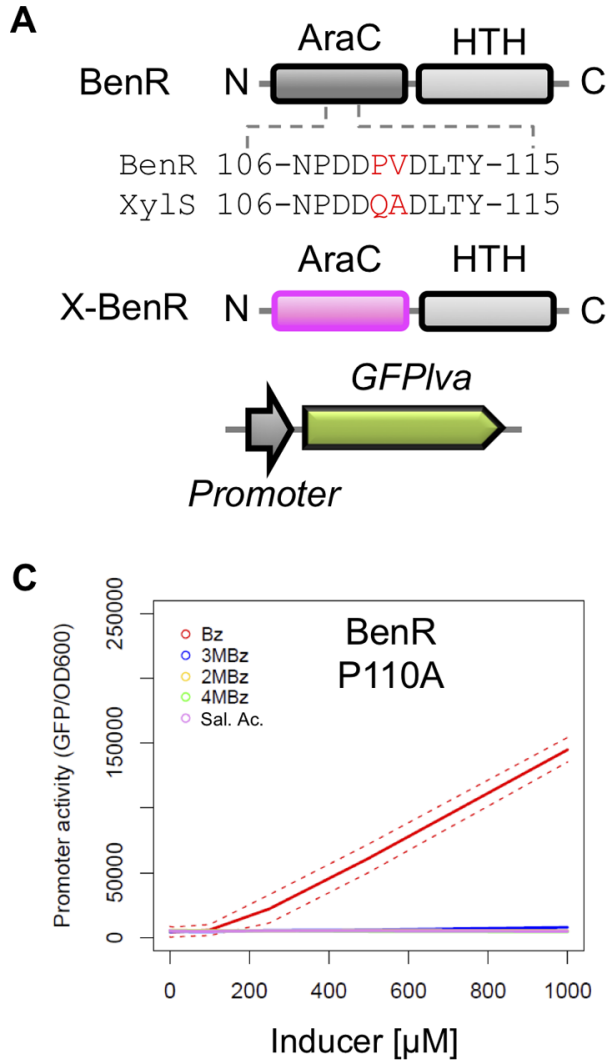

D

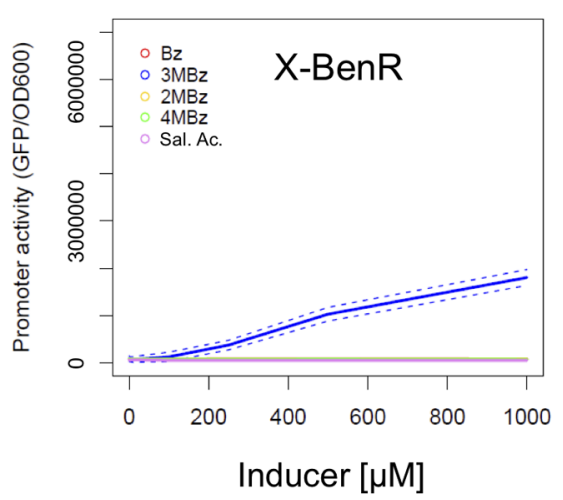

B
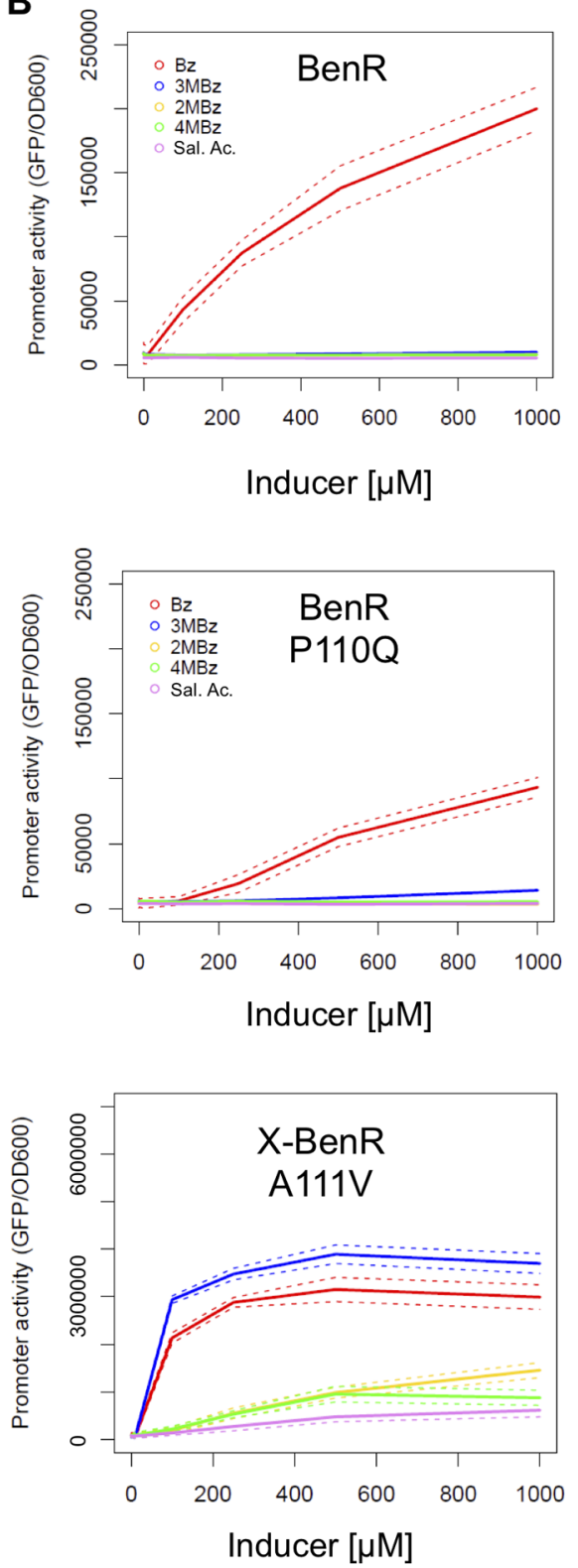
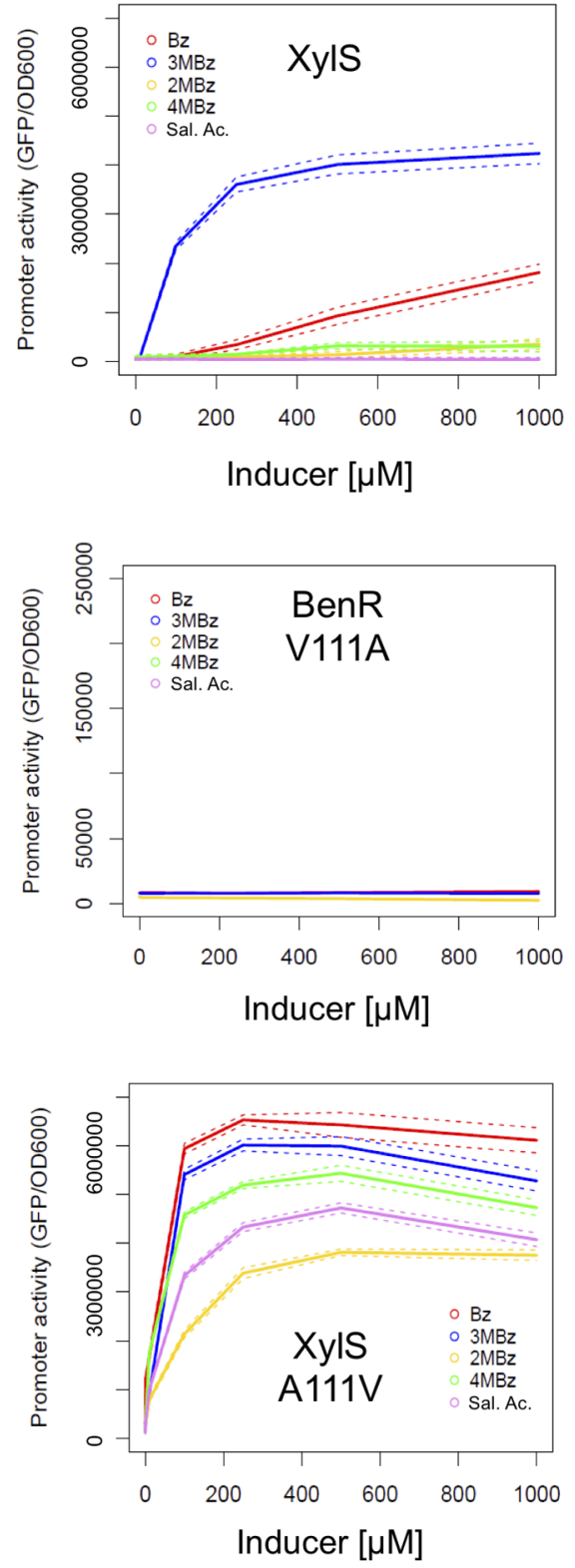

Figure 4. Experimental identification of critical aa's for inducer recognition in BenR and XylS. (A) Schematic representation of BenR and the chimeric protein X-BenR (a fusion between the N-terminal domain of XylS with the C-terminal domain of BenR), showing the nonconserved positions 110 and 111 tested here. All protein variants were tested with a GFPlva reporter under the control of the cognate promoter (i.e., $P b$ for BenR and X-BenR and Pm for XylS). (B) Analysis of the promoter activity of BenR-Pb and XylS-Pm in response to different concentrations of benzoate $(\mathrm{Bz}), 3$-methylbenzoate $(3 \mathrm{MBz})$, 2-methylbenzoate $(2 \mathrm{MBz})$, 4-methylbenzoate $(4 \mathrm{MBz})$, and salicylic acid (Ac Sal). The solid line indicates the average from three independent experiments, whereas the dashed lines represent the lower and higher limits of the standard deviation. (C) Analysis of the promoter activity for BenR mutants at positions 110 (BenR-P110A and BenR-P110Q) and 111 (BenR-V111A). (D) Analysis of the promoter activity for chimeric X-BenR protein and its variant with a mutation in position 111 (X-BenR-A111V) as well as for the mutated version of XylS (XylS-A111V). The promoter activities (panels B-D) reported here were calculated after $5 \mathrm{~h}$ of exposure to the different inducers.

protein (GFP) reporter gene (Figure 4A) to allow investigation at the single-cell level ${ }^{34,35}$ (Figures S3-S5). The promoter activities were calculated after $5 \mathrm{~h}$ of exposure to the different inducers. As can be observed in Figure 4B, wild-type BenR was specific to benzoate at all concentrations tested, whereas wild-type XylS displayed a preferential response to $3 \mathrm{MBz}$, an intermediated response to benzoate, and a lower response to $2 \mathrm{MBz}$ and $4 \mathrm{MBz}$. When we mutated position 110 of BenR from Pro to Ala or Gln (the aa found at this position in XylS), we could observe that the mutants presented the same expression profile as the wild type but with reduced efficacy (Figure 4C). However, when position 111 was changed from $\mathrm{Val}$ to $\mathrm{Ala}$ in BenR, the resulting protein variant did not display any response to the inducers tested. Contrary to the expected, this change (Val 111 to Ala) did not widen the inducer specificity of BenR. By the same token, the construction of BenR mutants with changes at both positions 110 and 111 also resulted in nonfunctional proteins (Figure S1), potentially due to the role of Val111 in signal recognition. Therefore, it is worth noticing that the exchange of a shorter side-chain aa (Ala) for a major side-chain aa (Val) does not necessarily result in a spatial decrease in the aa binding pocket. 
A
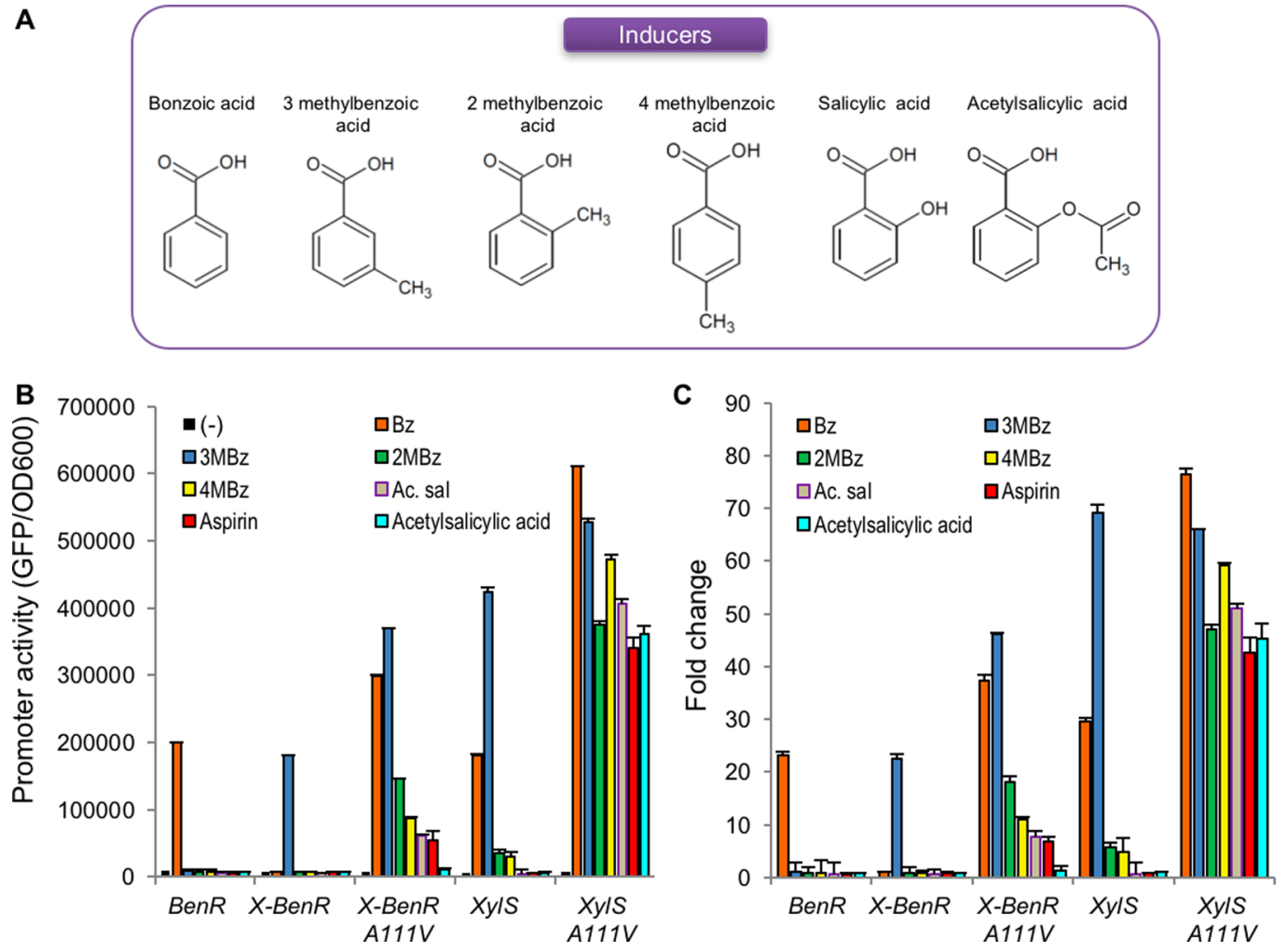

Figure 5. Analysis of transcriptional response to aromatic compounds and aspirin. (A) Schematic representation of the chemical structure of the different inducers tested. (B) Promoter activity of the different proteins reported here after $3 \mathrm{~h}$ of exposure to the different inducers. (All compounds were tested at $1 \mathrm{mM}$.) Aspirin refers to the commercial formulation obtained from a conversional drug store (with concentration adjusted to $100 \mu \mathrm{M}$ ), whereas acetylsalicylic acid specifies the pure compound obtained from Sigma-Aldrich. (C) Fold change calculated for each expression system in response to the different inducers used. Error bars represent the standard deviations from three independent experiments.

Taken together, these results indicate that Val111 is key for inducer recognition by BenR, and it is possible that it is related to the strengthening of its association with the effector binding pocket identified by homology modeling and molecular docking.

The construction of the chimeric protein harboring the $\mathrm{N}$ terminal of XylS (the region responsible for ligand recognition) and the $\mathrm{C}$-terminal of BenR (which recognizes DNA) resulted in the new protein $\mathrm{X}$-BenR that displayed an induction profile similar to that of XylS for the $3 \mathrm{MBz}$ induction but with a reduced efficacy (Figure 4D). However, X-BenR increased its inducer response to $3 \mathrm{MBz}$ at the same level as that which BenR responds to $\mathrm{Bz}$ (Figure 4D and Figure S2), perhaps because $\mathrm{Pm}$ has a higher promoter activity than $\mathrm{Pb}$. To check the role of position 111 in the inducer selectivity of XylS, we constructed point mutations of XylS and X-BenR by changing the alanine at this position for a valine. Unexpectedly, the resulting mutant proteins displayed an enhanced response to the optimal inducer $(3 \mathrm{MBz})$ as well as to the suboptimal inducers benzoate, $2 \mathrm{MBz}, 4 \mathrm{MBz}$, and salicylic acid (Figure 4D). From these results, it appears that the C-terminal of BenR does not allow as much promiscuity as that found in XylS. These results strengthen the notion that the required elements for inducer selectivity are placed in the first 196 aa's of these proteins, ${ }^{36}$ although the effector response is not completely independent of, but is also related to, the C-terminal DNAbinding domain. Finally, attempts to construct a chimeric protein harboring the $\mathrm{N}$-terminal of BenR and the C-terminal of XylS (named B-XylS) resulted in nonfunctional products with no detectable response to benzoate or $3 \mathrm{MBz}$ (Figure S2).
Yet the single-cell analysis of promoter induction by flow cytometry showed that whereas wild-type BenR- and XylSbased expression systems presented clear unimodal patterns (i.e., with a single population of fluorescent cells), the X-BenR chimaera and mutated versions of XylS and X-BenR displayed a wider population distribution that could indicate stable subpopulations (Figures S3-S5). Taken together, these results evidenced a remarkably different role of position 111 between BenR and XylS, which led to the identification of two TF variants with an enhanced response to a wide range of benzoate derivatives.

Transcriptional Factors Responsive to a New Set of Aromatic Compounds and Aspirin. After the inducer recognition profiles of BenR and XylS are characterized, we assay the TF variants for a new set of inductors. Figure 5 represents the overall performances of the TFs in response to a new set of benzoate derivatives (Figure 5A). As shown in Figure 5B, BenR $(P b$-BenR) and X-BenR (X-BenR/Pb) produced the lowest promoter outputs and were exclusively responsive to benzoate (BenR) or $3 \mathrm{MBz}$ (X-BenR). Because these proteins have a BenR C-terminal domain, they can recognize both $\mathrm{Pm}$ and $\mathrm{Pb}$. On the contrary, XylS has an intermediate level of promoter output and a preference for $3 \mathrm{MBz}$, followed by benzoate, and only a minor response to $2 \mathrm{MBz}$ and $4 \mathrm{MBz}$. Yet the mutated version of X-BenR (XBenR-A $111 \mathrm{~V} / \mathrm{Pb}$ ) promoted an overall increased response to the suboptimal inducers of XylS $(\mathrm{XylS} / \mathrm{Pm})$ and also a response to aspirin and ASA. Finally, the mutated version of XylS (XylS-A111V) displays a remarkable gain of response to all benzoate derivatives tested, including aspirin and ASA, with 
promoter outputs similar to those of wild-type XylS induced with its optimal effector $3 \mathrm{MBz}$ (Figure 5B). When fold-change is calculated relative to noninduced conditions, it can be noticed that the maximal induction of the XylS-A111V (XylSA111V/Pm) system ( 76-fold) exceeds that of the wild-type XylS ( $\sim 69$-fold, Figure $5 \mathrm{C}$ ). In this new system, the response to ASA reaches 42 - and 45-fold, respectively, yet because this enhanced response could be the result of the construction of a TF with a promiscuous effector specificity, we tested the response of XylS-A111V to toluene, xylene, phenol, and a number of nonaromatic inducers (L-arabinose, fructose, glucose, isopropyl $\beta$-D-1-thiogalactopyranoside (IPTG), and arsenite; Figure S6A). As can be observed in Figure S6B, the system did not respond to any of these compounds, whereas further tests with vanillin, 4-hydroxybenzoic acid, and benzilic alcohol also show only a minor effect of this last compound on the activity of X-BenR-A111V and XylS-A111V (Figure S6C). Taken together, these data show that benzoate analogues are the preferential inducers of the newly generated systems described here.

Promoter Engineering Further Enhances X-BenRA111V Response to Nonoptimal Inducers. The data presented above demonstrate how changes in the aa sequence of BenR and XylS could drastically change the inducer specificity of these two regulators, yet, in the case of BenR, previous studies by our group have demonstrated that changes in the operator sequence of its target promoter $(\mathrm{Pb})$ could also impact the way this regulator responds to suboptimal inducers. More specifically, because $P b$ is formed by one complete operator sequence (harboring boxes A and B, Figure 1B) plus another incomplete operator (where the A box is missing), the addition of the A box to restore the second binding site makes the $\mathrm{BenR} / \mathrm{Pb}$ system more responsive to the suboptimal inducer $3 \mathrm{MBz} .{ }^{27}$ In this sense, because we noticed a gain of function for the X-BenRA111V chimeric protein constructed here, we decided to investigate if this regulator would have an improved response to the new inducers when activating a mutated version of $\mathrm{Pb}$ harboring two functional operators $(\mathrm{Pb}$ syn1, Figure 6A). As shown in Figure 6B, the newly created XBenR-A $111 \mathrm{~V}$ regulators displayed an increased response to most inducers tested, with a more than two-fold change in promoter activity when induced with $\mathrm{Bz}, 3 \mathrm{MBz}, 2 \mathrm{MBz}$, and $4 \mathrm{MBz}$. These results confirm the previous notion that promoter architecture is an important element controlling the inducer response to suboptimal inducers in BenR regulators and also adds a new modulation level (the promoter itself) for the optimization of biosensors from the XylS family.

\section{DISCUSSION}

The results presented here shed some light on the molecular mechanisms for ligand and promoter recognition of BenR and XylS from $P$. putida. Of particular interest, XylS has been extensively investigated both in the context of the natural regulation of the meta pathways in P. putida mt- $2^{37-39}$ as well as for its applicability as a universal expression system for Gram-negative bacteria. ${ }^{12,40,41}$ Previous attempts have investigated the critical aa for inducer recognition and promoter activation, ${ }^{12,32,42}$ but these studies have not provided a clear molecular proposition on how this protein interacts with its ligands or the promoter. On the contrary, fewer studies have investigated BenR at the molecular level. ${ }^{26,27,43}$ As for the findings presented here, we initially expect that changes in the aa of the identified binding pocket of BenR could adjust the
A
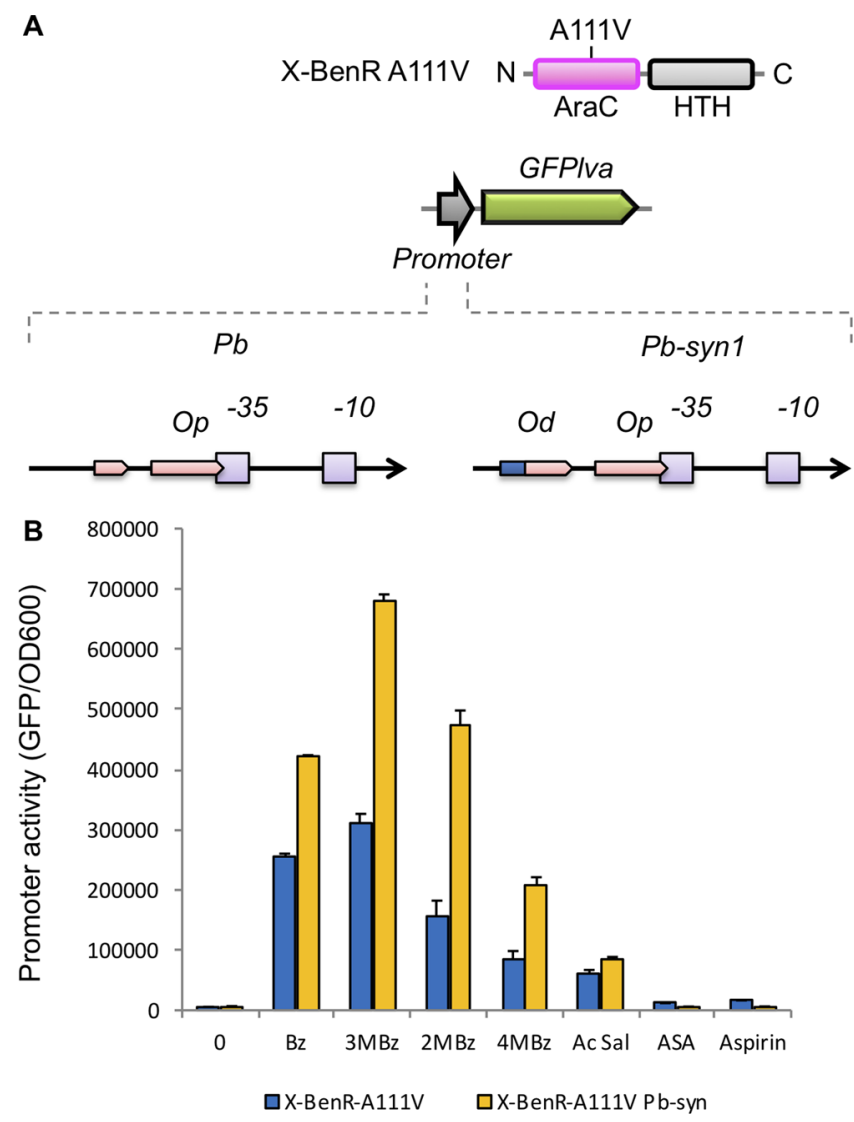

Figure 6. Effect of promoter architecture on the sensitivity of the XBenR A111V regulator. (A) Schematic representation of the assayed system, where a wild-type or a synthetic $\mathrm{Pb}$ promoter ${ }^{27}$ harboring a completed $O p$ binding site has been used to control GFP expression. (B) Analysis of promoter activity for the X-BenR A111V mutant in response to benzoate $(\mathrm{Bz})$, 3-methylbenzoate $(3 \mathrm{MBz})$, 2-methylbenzoate $(2 \mathrm{MBz})$, 4-methylbenzoate $(4 \mathrm{MBz})$, salicylic acid (Ac Sal), acetyl salicylic acid (ASA), and aspirin. All inducers were used at 100 $\mu \mathrm{M}$. Vertical bars are the standard deviations from three independent experiments.

ligand selectivity of the protein, as reported for the $\mathrm{TtgV}$ regulator that can discriminate between molecules with one or two aromatic rings. ${ }^{44,45}$ Yet, contrary to the initial size exclusion model proposed, our experimental validation of the binding site prediction supports a role for position 111 in both BenR and XylS as a key element connecting the binding of the ligand to the changes in domain arrangement of the protein, similarly to the mechanism of activation of AraC of E. coli. ${ }^{46}$ In this sense, the modeling of BenR with both $\mathrm{N}$ - and C-terminal domains suggests that residue 111 is close to the interface between the ligand binding and DNA binding domains (Figures S7, S8, and S10). In this scenario, valine could make critical interactions in BenR that are disrupted when this aa is changed for alanine. In the same way, changing alanine in XylS (or in X-BenR) for valine would allow the establishment of novel interactions that could enhance the performance of the protein, allowing the recognition of novel inducers such as salicylate or ASA. Previous work aiming at the construction of a XylS- $P m$ expression cassette with an increased response to $3 \mathrm{MBz}$ has reported several mutations in both the $\mathrm{N}$ - and $\mathrm{C}$ terminal regions of XylS. Among these mutants, an A111V mutation has been reported before, also based on the 3D modeling of XylS, suggesting that this A111 residue interacts 
Table 1. Strains and Plasmids Used in This Work

\begin{tabular}{|c|c|c|}
\hline strains and plasmids & description & reference \\
\hline \multicolumn{3}{|l|}{ Strains } \\
\hline P. putida KT2440 & P. putida mt-2 derivative & 59 \\
\hline E. coli $\mathrm{DH} 5 \alpha$ & F- $\varphi 80 \Delta$ lacZ $\Delta$ M15 $\Delta$ (lacZYAA-argF) U169 recA1 endA1 hsdR17 R-M+ supE4 thi gyrA relA & 50 \\
\hline \multicolumn{3}{|l|}{ Plasmids } \\
\hline pSEVA438 & $\mathrm{Sm} / \mathrm{Sp}^{\mathrm{R}}$, ori $\mathrm{pBBR} 1$; Expression vector harboring the $x y l S-P m$ expression system & 33 \\
\hline pSEVA226 & $\mathrm{Km}^{\mathrm{R}}$, ori $\mathrm{RK} 2$; reporter vector harboring the $l u x C D A B E$ operon & 33 \\
\hline pSEVA226-Pm & $\mathrm{Km}^{\mathrm{R}}$, ori RK2; pSEVA226 with the $P m$ promoter cloned as a $E c o \mathrm{RI} / B a m H I$ fragment & 27 \\
\hline pSEVA226-Pbsyn1 & $\mathrm{Km}^{\mathrm{R}}$, ori RK2; pSEVA226 with the Pbsyn1 promoter cloned as a EcoRI/BamHI fragment & 27 \\
\hline pMR1 & $\mathrm{Cm}^{\mathrm{R}}$, ori $\mathrm{p} 15 \mathrm{a}$; dual $\mathrm{mCherry/GFPlva}$ promoter probe vector & 51 \\
\hline pMR1-BenR-Pb & $C m^{\mathrm{R}}$, ori p15a; pMR1 variant with $b e n R-P b$ expression system closed as a $B g l \mathrm{II} / E c o \mathrm{RI}$ fragment & this study \\
\hline pMR1-BenR-V111A & $\mathrm{Cm}^{\mathrm{R}}$, ori $\mathrm{p} 15 \mathrm{a}$; pMR1-BenR-Pb with benR gene mutated at position V111A & this study \\
\hline pMR1-BenR-P110A & $\mathrm{Cm}^{\mathrm{R}}$, ori p15a; pMR1-BenR-Pb with benR gene mutated at position $\mathrm{P} 110 \mathrm{~A}$ & this study \\
\hline pMR1-BenR-P110Q & $\mathrm{Cm}^{\mathrm{R}}$, ori $\mathrm{p} 15 \mathrm{a}$; pMR1-BenR-Pb with benR gene mutated at position P110Q & this study \\
\hline pMR1-BenR-Q110A111 & $C m^{\mathrm{R}}$, ori $\mathrm{p} 15 \mathrm{a}$; pMR1-BenR-Pb with benR gene mutated at positions $\mathrm{P} 110 \mathrm{Q}$ and $\mathrm{V} 111 \mathrm{~A}$ & this study \\
\hline pMR1-X-BenR & $C m^{\mathrm{R}}$, ori $\mathrm{p} 15 \mathrm{a}$; pMR1-BenR-Pb with benR with the $\mathrm{N}$-terminal region replaced by that of $x y l S$ & this study \\
\hline pMR1- X-BenR-A111V & $\mathrm{Cm}^{\mathrm{R}}$, ori $\mathrm{p} 15 \mathrm{a}$; pMR1-X-BenR with chimeric X-benR gene mutated at position A111V & this study \\
\hline pMR1-XylS-Pm & $C m^{\mathrm{R}}$, ori p15a; pMR1 variant with $x y l S-P m$ expression system closed as a $B g l \mathrm{II} / E c o \mathrm{RI}$ fragment & this study \\
\hline pMR1-XylS-Pm-A111V & $C m^{\mathrm{R}}$, ori p15a; pMR1-XylS-Pm with $x y l S$ gene mutated at position A111V & this study \\
\hline pMR1-B-XylS & $C m^{\mathrm{R}}$, ori p15a; pMR1-XylS-Pm with $x y l S$ with the $\mathrm{N}$-terminal region replaced by that of $b e n R$ & this study \\
\hline
\end{tabular}

with the effector binding pocket. However, in this work, authors performed the A111V mutation together with one or two additional aa positions. ${ }^{12}$ Therefore, the role of position 111 in XylS has never been investigated in isolation. It was interesting to notice that changing the promoter architecture of $\mathrm{Pb}$ allowed the increased responsivity of the chimeric X-BenRA111V to benzoate analogues, yet this strategy was not able to improve the responsivity to ASA or aspirin. This could indicate that the responsivity to these two compounds would require some additional interactions with the TF that are possible only in XylS, and this should be further investigated in the future. Additionally, most of the previously reported mutations affecting the XylS inducer response specificity are located close to the predicted binding pocket identified in this work (Figure S9), increasing the confidence of the computational approach used here.

It is interesting to notice that the mutations affecting the signal specificity of BenR and XylS either completely abolish the protein activity or generate regulators with an enhanced response to a series of ligands. In other words, it was not possible to switch the specificity of the ligand-binding domains from one compound to another. This notion resembles the stem protein model investigated for XylR (another aromatic responsive regulator from $P$. putida $\mathrm{mt}-2$ ), where the selection of mutant proteins responsive to new ligands resulted in variants promiscuous to several aromatic compounds. ${ }^{47}$ It is also important to notice that the computational approach used here predicted the ligand binding pocket site together with the conservation analysis of phylogenetically related protein homologues, which represents a powerful tool to guide the rational design of TF variants. Similar approaches could be applied to other members of the AraC/XylS family of TFs as well as to regulators from different families, aiming at the generation of novel expression systems for inducers of interest. Additionally, recent approaches based on the construction and high-throughput characterization of chimeric proteins have been used to create new benzoate responsive regulators. Yet this approach has generated very modest induction levels for the final engineered proteins (with approximately three-fold changes), whereas the approach used here yielded an induction of about 40 times for the mutated version of XylS. ${ }^{48}$ Whereas $\mathrm{NahR}$, a LysR-type transcriptional regulator, is able to induce gene expression in response to salicylate, ${ }^{10}$ the TFs engineered here represent a new set of tools for the expression of genes of interest in response to salicylate and ASA. Additionally, the expression system based on XylS-A111V displays a $\sim 10$-fold change in response to $10 \mu \mathrm{M}$ of ASA, which is in the same range of the observed sensitivity for the natural ASAresponsive regulator $\mathrm{NahR}$ (which reaches a 20-fold change in response to a similar concentration of the compound ${ }^{10}$ ). These concentrations are in the range of the physiological concentrations of ASA in blood, as this molecules can reach levels as high as $\sim 30 \mu \mathrm{M}$ after $20 \mathrm{~min}$ of administration of the drug. ${ }^{49}$ Yet, whereas the new aspirin-responsive regulator presented here is not specific to this compound, it is reasonable to think that during real applications (i.e., in vivo in a mammalian cell model), systems would not be exposed to benzoate or any of its analogues. Therefore, the lack of exclusive responsivity to aspirin would not be an issue under real case applications. Taken together, these results demonstrate the expansion of the genetic toolbox for the engineering of synthetic circuits inducible to safe drugs.

\section{MATERIALS AND METHODS}

Bacterial Strains and Growth Conditions. The plasmids and bacterial strains used in this study are listed in Table 1. Cloning and assay procedures were performed in E. coli DH5 $\alpha$. All DNA manipulations, including cloning, polymerase chain reaction (PCR), and transformations of $E$. coli, were performed according Sambrook et al. ${ }^{50}$ Bacterial strains were routinely grown in LB media supplemented with $36 \mu \mathrm{g} \mathrm{mL} \mathrm{m}^{-1}$ chloramphenicol or, when necessary, in $\mathrm{M} 9$ minimal media (6.4 $\mathrm{g} \mathrm{L}^{-1} \mathrm{Na}_{2} \mathrm{HPO}_{4} \cdot 7 \mathrm{H}_{2} \mathrm{O}, 1.5 \mathrm{~g} \mathrm{~L}^{-1} \mathrm{KH}_{2} \mathrm{PO}_{4}, 0.25 \mathrm{~g} \mathrm{~L}^{-1}$

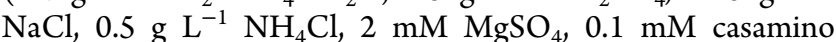
acids, $1 \%$ glycerol) supplemented with chloramphenicol at 36 $\mu \mathrm{g} \mathrm{mL}^{-1}$. Liquid cultures were shaken at $180 \mathrm{rpm}$ at $37^{\circ} \mathrm{C}$ for 
$\sim 16 \mathrm{~h}$. The aromatic compounds used as inducers were all purchased from Sigma-Aldrich. The inducers and their catalogue numbers are benzoic acid (242381), 3-methylbenzoic acid (3117714), 2-methylbenzoic acid (169978), 4methylbenzoic acid (117390), salicylic acid (S5922), ASA (A5376), Bayer aspirin (1000 $\mu \mathrm{M})$ and isopropyl $\beta$-D-1tiogalactopiranosida (IPTG) (I5502), sodium arsenite (S7400), toluene (244511), xylene (214736), phenol (P1037), L-arabinose (A3256), D-(-)-fructose (F0127), and D-(+)-glucose (G8270).

Plasmid Construction. The benR gene and $P b e n R$ and $P b$ promoters were amplified by PCR using specific primers (Table S1) and P. putida KT2440 genomic DNA as the template. The PCR products were digested with specific restriction enzymes (see the underlined sequences in Table S1) and cloned into the pMR1 vector, ${ }^{51}$ yielding the pMR1BenR-Pb (BenR) construct. BenR mutants, pMR1-BenRP110A (BenR-P110A), pMR1-BenR-P110Q (BenR-P110Q), pMR1-BenR-V111A (BenR-V111A), pMR1-BenR-A110A111 (BenR-A110A111), and pMR1-BenR-Q110A111 (BenRQ110A111), were generated by circular polymerase extension cloning (CPEC) site-directed mutagenesis methodology ${ }^{52}$ using the pMR1-BenR-Pb construct as the template and the primers listed in Table S1. (Mutated base pairs are highlighted in bold and underlined.) The $x y l S$ gene and $P s$ and $P m$ promoters were amplified by PCR using pSEVA438 vector as the template, ${ }^{33}$ yielding the pMR1-XylS-Pm (XylS) construct. XylS mutant pMR1-XylS-A111V (XylS-A111V) was constructed by CPEC site-directed mutagenesis using the pMR1-XylS-Pm construct as the template and the primers listed in Table S1. (Mutated base pairs are highlighted in bold and underlined.) Two chimeric transcription factors were constructed. The first construct was generated by directly linking the $\mathrm{N}$-terminal domain of XylS and the C-terminal domain of BenR using, respectively, $P$. putida $\mathrm{mt}-2$ and KT2440 strains as templates. The second construct was generated by linking the $\mathrm{N}$-terminal domain of BenR and the C-terminal domain of XylS using the pMR1-BenR- $P b$ and the pMR1-XylS- $P m$ as templates. All fragments were amplified by PCR. In the first construct, the PbenR promoter was cloned upstream the chimaera, and the $P b$ promoter was cloned upstream the GFPlva reporter gene, yielding the pMR1-XBenR (X-BenR). The chimaera mutant pMR1-X-BenR-A111V (X-BenR-A111V) was constructed using the vector pMR1-XBenR as the template. In the second construct, the Ps and Pm promoters were cloned upstream the chimaera and the GFPlva reporter gene, respectively, generating the pMR1-B-XylS (BXylS). All PCR amplifications were performed using Phusion high-fidelity DNA polymerase (Thermo Fisher Scientific). All resulting constructs were sequenced using dideosyterminal methods to confirm the correct assembly prior to the fluorescence assays. The aa sequences of the final construct generated here are represented in Table S2.

GFP Fluorescence Assay and Data Processing. To measure the activity of all constructions performed in this work, plasmids were transformed into E. coli DH5 $\alpha$. Freshly plated single colonies were grown in M9 minimal media supplemented with suitable antibiotics. The cultures $(10 \mu \mathrm{L})$ were then assayed in a 96-well microplates with $170 \mu \mathrm{L}$ of M9 minimal media and $20 \mu \mathrm{L}$ of the different compounds tested. When required, benzoic acid $(\mathrm{Bz}), 3$-methylbenzoic acid $(3 \mathrm{MBz}), 2$-methylbenzoic acid $(2 \mathrm{MBz})$, 4-methylbenzoic acid $(4 \mathrm{MBz})$, salicylic acid $(0-1000 \mu \mathrm{M})$, ASA, Bayer aspirin
$(1000 \mu \mathrm{M})$ and IPTG, sodium arsenite, toluene, xylene, phenol, L-arabinose, fructose, and glucose $(100 \mu \mathrm{M})$ were used. Cell growth and GFP fluorescence were quantified using a Victor X3 plate reader (PerkinElmer). The responsiveness of regulators was calculated as arbitrary units using the ratio between fluorescence levels and the optical density at $600 \mathrm{~nm}$ (reported as $\mathrm{GFP} / \mathrm{OD}_{600}$ ) or the luminescence by optical density at $600 \mathrm{~nm}$ after background correction. As a control, all assays were performed without the addition of compounds (inducers) as the threshold background signal during calculations. Fluorescence and absorbance measurements were taken at $30 \mathrm{~min}$ intervals up to $8 \mathrm{~h}$ at $37^{\circ} \mathrm{C}$. All experiments were performed in technical and biological triplicates. Raw data were processed using ad hoc $\mathrm{R}$ script (https://www.r-project.org/).

Flow Cytometry Analysis. High-throughput single-cell analysis of the bacteria carrying the BenR, XylS, XBenR, XylS mutant, or XBenR mutant systems was run as follows. First, we selected single colonies of the transformed strain (E. coli $\mathrm{DH} 5 \alpha$ ) and cultivated it overnight in $\mathrm{M} 9$ minimal medium (containing $6.4 \mathrm{~g} / \mathrm{L} \mathrm{Na} \mathrm{HPO}_{4} \cdot 7 \mathrm{H}_{2} \mathrm{O}, 1.5 \mathrm{~g} / \mathrm{L} \mathrm{KH}_{2} \mathrm{PO}_{4}, 0.25$ $\mathrm{g} / \mathrm{L} \mathrm{NaCl}$, and $0.5 \mathrm{~g} / \mathrm{L} \mathrm{NH} 4 \mathrm{Cl}$ ) supplemented with $2 \mathrm{mM}$ $\mathrm{MgSO}_{4}, 0.1 \mathrm{mM} \mathrm{CaCl} 2,0.1 \mathrm{mM}$ casamino acids, chloramphenicol $(36 \mu \mathrm{g} / \mathrm{mL})$, and $1 \%$ glycerol as the sole carbon source (supplemented M9) at $37{ }^{\circ} \mathrm{C}$ and $180 \mathrm{rpm}$. Next, overnight grown cells were diluted to $1: 10$ in fresh supplemented M9 and were grown for $3 \mathrm{~h}$ at $37{ }^{\circ} \mathrm{C}$ and 180 $\mathrm{rpm}$. At this point, the cultures were induced with different concentrations $(0,10,100,250,500$, and $1000 \mu \mathrm{M})$ of the inducers. The BenR system was induced with benzoate, XylS was induced with benzoate and 3-metilbenzoate, X-BenR was induced with 3-metilbenzoate, and XylS mutant and X-BenR mutant were induced with benzoate, 3-metil-benzoate, salicylic acid, and acetyl-salicylic acid. After $3 \mathrm{~h}$ of induction, the cultures were stored in ice and immediately analyzed for GFP fluorescence using the Millipore Guava EasyCyte mini flow cytometer (Millipore). The results were analyzed by $\mathrm{R}$ scripts using the flowCore and flowViz packages available on Bioconductor (https://bioconductor.org/).

3D Structure Model Construction and Docking Analysis. The 3D models presented here were generated by SWISS-MODEL server (https://swissmodel.expasy.org/) using the best homologue for each protein. For the visualization of the models, PyMol (https://pymol.org/) and Chimaera (https://www.cgl.ucsf.edu/chimera/) were used. To predict the potential binding site for the aromatic ligands, Swiss-Docking (https://www.swissdock.ch/) and Docking Server (https://www.dockingserver.com/web) were used. Additionally, Jalview (http://www.jalview.org/) was used for the visualization of protein and DNA alignments generated by T-coffee (http://tcoffee.crg.cat/apps/tcoffee/all.html). From the generated 3D models using SwissModel, ${ }^{53}$ models were first inspected visually for histidine protonation and Asn and Gln positioning. Models were further refined by minimizing their structure with the AMBER FF14SB ${ }^{54}$ force field using AMBER. $^{55}$

Molecular Docking. The energy maps were computed inside the grid, with a grid size of $26 \times 30 \times 40$. Dockings were carried out using the LGA/LS algorithm implemented on Autodock $4^{56}$ (version 4.2.6, with a maximum of 27000 generations or 2500000 energy evaluations). Fifty independent runs were performed, and the resulting poses were clustered according to the ligand heavy-atom rmsd using a 
cutoff of $2 \AA$, thus defining a result. 3D structures of the ligands were generated using OpenBabel ${ }^{57}$ and manually inspected. Images were created with VMD. ${ }^{58}$

\section{ASSOCIATED CONTENT}

\section{S Supporting Information}

The Supporting Information is available free of charge on the ACS Publications website at DOI: 10.1021/acssynbio.9b00191.

Protein sequences reported here and Figures $\mathrm{S} 1-\mathrm{S} 10$ and Tables S1-S3 (PDF)

\section{AUTHOR INFORMATION}

\section{Corresponding Author}

*Tel: +55 163602 3107. Fax: +55 163633 6840. E-mail: silvarochar@usp.br.

\section{ORCID}

Lucas Defelipe: 0000-0001-7859-7300

Víctor de Lorenzo: 0000-0002-6041-2731

Rafael Silva-Rocha: 0000-0001-6319-631X

\section{Notes}

The authors declare no competing financial interest.

\section{ACKNOWLEDGMENTS}

We thank the lab members for insightful discussion on this work. We thank Gabriel Lencione Lovate for help with acquiring some chemicals used in this work. R.S.-R. and M.E.G. were supported by Young Research Awards, grant nos. 2012/22921-8 and 2015/04309-1, São Paulo Research Foundation (FAPESP). L.M.O.M., A.S.-M., L.M.-S., and L.F.A. were supported by FAPESP Ph.D. Fellowships (grant nos. 2016/19179-9, 2016/06323-4, 2017/17924-1, and 2018/ 04810-0).

\section{REFERENCES}

(1) Browning, D. F., and Busby, S. J. W. (2016) Local and Global Regulation of Transcription Initiation in Bacteria. Nat. Rev. Microbiol. $14,638-650$.

(2) Galán-Vásquez, E., Sánchez-Osorio, I., and Martínez-Antonio, A. (2016) Transcription Factors Exhibit Differential Conservation in Bacteria with Reduced Genomes. PLoS One 11 (1), e0146901.

(3) Gama-Castro, S., Salgado, H., Santos-Zavaleta, A., LedezmaTejeida, D., Muñiz-Rascado, L., García-Sotelo, J. S., AlquiciraHernández, K., Martínez-Flores, I., Pannier, L., Castro-Mondragón, J. A., Medina-Rivera, A., Solano-Lira, H., Bonavides-Martínez, C., Pérez-Rueda, E., Alquicira-Hernández, S., Porrón-Sotelo, L., LópezFuentes, A., Hernández-Koutoucheva, A., Del Moral-Chávez, V., Rinaldi, F., and Collado-Vides, J. (2016) RegulonDB Version 9.0: High-Level Integration of Gene Regulation, Coexpression, Motif Clustering and Beyond. Nucleic Acids Res. 44, D133-D143.

(4) Steinacher, A., Bates, D. G., Akman, O. E., and Soyer, O. S. (2016) Nonlinear Dynamics in Gene Regulation Promote Robustness and Evolvability of Gene Expression Levels. PLoS One 11 (4), e0153295.

(5) Baumstark, R., Hänzelmann, S., Tsuru, S., Schaerli, Y., Francesconi, M., Mancuso, F. M., Castelo, R., and Isalan, M. (2015) The Propagation of Perturbations in Rewired Bacterial Gene Networks. Nat. Commun. 6, 10105.

(6) Mannan, A. A., Liu, D., Zhang, F., and Oyarzun, D. A. (2017) Fundamental Design Principles for Transcription-Factor-Based Metabolite Biosensors. ACS Synth. Biol. 6 (10), 1851-1859.

(7) Lee, J. W., Gyorgy, A., Cameron, D. E., Pyenson, N., Choi, K. R., Way, J. C., Silver, P. A., Del Vecchio, D., and Collins, J. J. (2016) Creating Single-Copy Genetic Circuits. Mol. Cell 63 (2), 329-336.
(8) Nielsen, A. a K., Der, B. S., Shin, J., Vaidyanathan, P., Paralanov, V., Strychalski, E. a, Ross, D., Densmore, D., and Voigt, C. a. (2016) Genetic Circuit Design Automation. Science 352 (6281), aac7341.

(9) Unkles, S. E., Valiante, V., Mattern, D. J., and Brakhage, A. A. (2014) Synthetic Biology Tools for Bioprospecting of Natural Products in Eukaryotes. Chem. Biol. 21 (4), 502-508.

(10) Shin, H. J. (2010) Development of Highly-Sensitive Microbial Biosensors by Mutation of the NahR Regulatory Gene. J. Biotechnol. 150 (2), 246-250.

(11) Garmendia, J., de las Heras, A., Galvao, T. C., and de Lorenzo, V. (2008) Tracing Explosives in Soil with Transcriptional Regulators of Pseudomonas Putida Evolved for Responding to Nitrotoluenes. Microb. Biotechnol. 1 (3), 236-246.

(12) Vee Aune, T. E., Bakke, I., Drablos, F., Lale, R., Brautaset, T., and Valla, S. (2010) Directed Evolution of the Transcription Factor XylS for Development of Improved Expression Systems. Microb. Biotechnol. 3 (1), 38-47.

(13) Bates, D. M., Popescu, C. V., Khoroshilova, N., Vogt, K., Beinert, H., Munck, E., and Kiley, P. J. (2000) Substitution of Leucine 28 with Histidine in the Escherichia Coli Transcription Factor FNR Results in Increased Stability of the [4Fe-4S](2+) Cluster to Oxygen. J. Biol. Chem. 275 (9), 6234-6240.

(14) Chen, J. X., Steel, H., Wu, Y. H., Wang, Y., Xu, J., Rampley, C. P. N., Thompson, I. P., Papachristodoulou, A., and Huang, W. E. (2019) Development of Aspirininducible Biosensors in Escherichia Coli and SimCells. Appl. Environ. Microbiol. 85, No. e02959-18.

(15) Meyer, A. J., Segall-Shapiro, T. H., Glassey, E., Zhang, J., and Voigt, C. A. (2019) Escherichia Coli "Marionette" Strains with 12 Highly Optimized Small-Molecule Sensors. Nat. Chem. Biol. 15, 196.

(16) Shis, D. L., Hussain, F., Meinhardt, S., Swint-Kruse, L., and Bennett, M. R. (2014) Modular, Multi-Input Transcriptional Logic Gating with Orthogonal LacI/GalR Family Chimeras. ACS Synth. Biol. 3 (9), 645-651.

(17) Younger, A. K., Dalvie, N. C., Rottinghaus, A. G., and Leonard, J. N. (2017) Engineering Modular Biosensors to Confer MetaboliteResponsive Regulation of Transcription. ACS Synth. Biol. 6 (2), 311325

(18) Stanton, B. C., Nielsen, A. A., Tamsir, A., Clancy, K., Peterson, T., and Voigt, C. A. (2014) Genomic Mining of Prokaryotic Repressors for Orthogonal Logic Gates. Nat. Chem. Biol. 10 (2), 99-105.

(19) Libis, V., Delepine, B., and Faulon, J. L. (2016) Sensing New Chemicals with Bacterial Transcription Factors. Curr. Opin. Microbiol. 33, 105-112.

(20) Bikard, D., Jiang, W., Samai, P., Hochschild, A., Zhang, F., and Marraffini, L. A. (2013) Programmable Repression and Activation of Bacterial Gene Expression Using an Engineered CRISPR-Cas System. Nucleic Acids Res. 41 (15), 7429-7437.

(21) Bikard, D., and Marraffini, L. A. (2013) Control of Gene Expression by CRISPR-Cas Systems. F1000Prime Rep. 5, 47.

(22) Qi, L. S., Larson, M. H., Gilbert, L. A., Doudna, J. A., Weissman, J. S., Arkin, A. P., and Lim, W. A. (2013) Repurposing CRISPR as an RNA-Guided Platform for Sequence-Specific Control of Gene Expression. Cell 152 (5), 1173-1183.

(23) Libis, V., Delepine, B., and Faulon, J. L. (2016) Expanding Biosensing Abilities through Computer-Aided Design of Metabolic Pathways. ACS Synth. Biol. 5 (10), 1076-1085.

(24) de los Santos, E. L., Meyerowitz, J. T., Mayo, S. L., and Murray, R. M. (2016) Engineering Transcriptional Regulator Effector Specificity Using Computational Design and In Vitro Rapid Prototyping: Developing a Vanillin Sensor. ACS Synth. Biol. 5 (4), 287-295.

(25) Royo, J. L., Becker, P. D., Camacho, E. M., Cebolla, A., Link, C. Santero, E., and Guzman, C. A. (2007) In Vivo Gene Regulation in Salmonella Spp. by a Salicylate-Dependent Control Circuit. Nat. Methods 4 (11), 937-942.

(26) Perez-Pantoja, D., Kim, J., Silva-Rocha, R., and de Lorenzo, V. (2015) The Differential Response of the Pben Promoter of 
Pseudomonas Putida Mt-2 to BenR and XylS Prevents Metabolic Conflicts in m-Xylene Biodegradation. Environ. Microbiol. 17, 64.

(27) Silva-Rocha, R., and de Lorenzo, V. (2012) Broadening the Signal Specificity of Prokaryotic Promoters by Modifying CisRegulatory Elements Associated with a Single Transcription Factor. Mol. BioSyst. 8 (7), 1950-1957.

(28) Cowles, C. E., Nichols, N. N., and Harwood, C. S. (2000) BenR, a XylS Homologue, Regulates Three Different Pathways of Aromatic Acid Degradation in Pseudomonas Putida. J. Bacteriol. 182 (22), 6339-6346.

(29) Xue, H., Shi, H., Yu, Z., He, S., Liu, S., Hou, Y., Pan, X., Wang, H., Zheng, P., Cui, C., Viets, H., Liang, J., Zhang, Y., Chen, S., Zhang, H. M., and Ouyang, Q. (2014) Design, Construction, and Characterization of a Set of Biosensors for Aromatic Compounds. ACS Synth. Biol. 3 (12), 1011-1014.

(30) Tobes, R., and Ramos, J. L. (2002) AraC-XylS Database: A Family of Positive Transcriptional Regulators in Bacteria. Nucleic Acids Res. 30 (1), 318-321.

(31) Kessler, B., de Lorenzo, V., and Timmis, K. N. (1993) Identification of a Cis-Acting Sequence within the Pm Promoter of the TOL Plasmid Which Confers XylS-Mediated Responsiveness to Substituted Benzoates. J. Mol. Biol. 230 (3), 699-703.

(32) Domínguez-Cuevas, P., Marín, P., Marqués, S., and Ramos, J. L. (2008) XylS-Pm Promoter Interactions through Two Helix-TurnHelix Motifs: Identifying XylS Residues Important for DNA Binding and Activation. J. Mol. Biol. 375 (1), 59-69.

(33) Silva-Rocha, R., Martínez-García, E., Calles, B., Chavarría, M., Arce-Rodríguez, A., de las Heras, A., Páez-Espino, A. D., DuranteRodríguez, G., Kim, J., Nikel, P. I., Platero, R., and de Lorenzo, V. (2013) The Standard European Vector Architecture (SEVA): A Coherent Platform for the Analysis and Deployment of Complex Prokaryotic Phenotypes. Nucleic Acids Res. 41 (D1), D666-D675.

(34) Silva-Rocha, R., and de Lorenzo, V. (2012) Stochasticity of TOL Plasmid Catabolic Promoters Sets a Bimodal Expression Regime in Pseudomonas Putida Mt-2 Exposed to m-Xylene. Mol. Microbiol. 86, 199.

(35) Silva-Rocha, R., and de Lorenzo, V. (2012) A GFP-LacZ Bicistronic Reporter System for Promoter Analysis in Environmental Gram-Negative Bacteria. PLoS One 7 (4), e34675.

(36) Michan, C., Zhou, L., Gallegos, M. T., Timmis, K. N., and Ramos, J. L. (1992) Identification of Critical Amino-Terminal Regions of Xy1S. The Positive Regulator Encoded by the TOL Plasmid. J. Biol. Chem. 267 (32), 22897-22901.

(37) Moreno, R., Fonseca, P., and Rojo, F. (2010) The Crc Global Regulator Inhibits the Pseudomonas Putida PWW0 Toluene/Xylene Assimilation Pathway by Repressing the Translation of Regulatory and Structural Genes. J. Biol. Chem. 285 (32), 24412-24419.

(38) Gonzalez-Perez, M. M., Ramos, J. L., and Marques, S. (2004) Cellular XylS Levels Are a Function of Transcription of XylS from Two Independent Promoters and the Differential Efficiency of Translation of the Two MRNAs. J. Bacteriol. 186 (6), 1898-1901.

(39) Marques, S., Manzanera, M., Gonzalez-Perez, M. M., Gallegos, M. T., and Ramos, J. L. (1999) The XylS-Dependent Pm Promoter Is Transcribed in Vivo by RNA Polymerase with Sigma 32 or Sigma 38 Depending on the Growth Phase. Mol. Microbiol. 31 (4), 1105-1113.

(40) Blatny, J. M., Brautaset, T., Winther-Larsen, H. C., Karunakaran, P., and Valla, S. (1997) Improved Broad-Host-Range RK2 Vectors Useful for High and Low Regulated Gene Expression Levels in Gram-Negative Bacteria. Plasmid 38 (1), 35-51.

(41) Blatny, J. M., Brautaset, T., Winther-Larsen, H. C., Haugan, K., and Valla, S. (1997) Construction and Use of a Versatile Set of BroadHost-Range Cloning and Expression Vectors Based on the RK2 Replicon. Appl. Environ. Microbiol. 63 (2), 370-379.

(42) Dominguez-Cuevas, P., Marin, P., Busby, S., Ramos, J. L., and Marques, S. (2008) Roles of Effectors in XylS-Dependent Transcription Activation: Intramolecular Domain Derepression and DNA Binding. J. Bacteriol. 190 (9), 3118-3128.

(43) Moreno, R., and Rojo, F. (2008) The Target for the Pseudomonas Putida Crc Global Regulator in the Benzoate
Degradation Pathway Is the BenR Transcriptional Regulator. J. Bacteriol. 190 (5), 1539-1545.

(44) Guazzaroni, M. E., Gallegos, M. T., Ramos, J. L., and Krell, T. (2007) Different Modes of Binding of Mono- and Biaromatic Effectors to the Transcriptional Regulator TTGV: Role in Differential Derepression from Its Cognate Operator. J. Biol. Chem. 282 (22), 16308-16316.

(45) Guazzaroni, M. E., Krell, T., Felipe, A., Ruiz, R., Meng, C., Zhang, X., Gallegos, M. T., and Ramos, J. L. (2005) The Multidrug Efflux Regulator TtgV Recognizes a Wide Range of Structurally Different Effectors in Solution and Complexed with Target DNA: Evidence from Isothermal Titration Calorimetry. J. Biol. Chem. 280 (21), 20887-20893.

(46) Schleif, R. (2010) AraC Protein, Regulation of the l-Arabinose Operon in Escherichia Coli, and the Light Switch Mechanism of AraC Action. FEMS Microbiol. Rev. 34 (5), 779-796.

(47) Galvao, T. C., Mencia, M., and de Lorenzo, V. (2007) Emergence of Novel Functions in Transcriptional Regulators by Regression to Stem Protein Types. Mol. Microbiol. 65 (4), 907-919.

(48) Juárez, J. F., Lecube-Azpeitia, B., Brown, S. L., Johnston, C. D., and Church, G. M. (2018) Biosensor Libraries Harness Large Classes of Binding Domains for Construction of Allosteric Transcriptional Regulators. Nat. Commun. 9, 3101.

(49) Cotty, V. F., Sterbenz, F. J., Mueller, F., Melman, K., Ederma, H., Skerpac, J., Hunter, D., and Lehr, M. (1977) Augmentation of Human Blood Acetylsalicylate Concentrations by the Simultaneous Administration of Acetaminophen with Aspirin. Toxicol. Appl. Pharmacol. 41 (1), 7-13.

(50) Sambrook, J., Fritsch, E. F., and Maniatis, T. (1989) Molecular Cloning: A Laboratory Manual, Cold Spring Harbor, New York.

(51) Guazzaroni, M.-E., and Silva-Rocha, R. (2014) Expanding the Logic of Bacterial Promoters Using Engineered Overlapping Operators for Global Regulators. ACS Synth. Biol. 3, 666-675.

(52) Quan, J., and Tian, J. (2011) Circular Polymerase Extension Cloning for High-Throughput Cloning of Complex and Combinatorial DNA Libraries. Nat. Protoc. 6 (2), 242-251.

(53) Biasini, M., Bienert, S., Waterhouse, A., Arnold, K., Studer, G., Schmidt, T., Kiefer, F., Cassarino, T. G., Bertoni, M., Bordoli, L., and Schwede, T. (2014) SWISS-MODEL: Modelling Protein Tertiary and Quaternary Structure Using Evolutionary Information. Nucleic Acids Res. 42, W252.

(54) Maier, J. A., Martinez, C., Kasavajhala, K., Wickstrom, L., Hauser, K. E., and Simmerling, C. (2015) Ff14SB: Improving the Accuracy of Protein Side Chain and Backbone Parameters from Ff99SB. J. Chem. Theory Comput. 11, 3696.

(55) Case, D. A., Betz, R. M., Cerutti, D. S., Cheatham, T. E., Darden, T. A., Duke, R. E., Giese, T. J., Gohlke, H., Goetz, A. W., Homeyer, N., Izadi, S., Janowski, P., Kaus, J., Kovalenko, A., Lee, T. S., LeGrand, S., Li, P., Lin, C., Luchko, T., Luo, R., Madej, B., Mermelstein, D., Merz, K. M., Monard, G., Nguyen, H., Nguyen, H. T., Omelyan, I., Onufriev, A., Roe, D. R., Roitberg, A., Sagui, C., Simmerling, C. L., Botello-Smith, W. M., Swails, J., Walker, R. C., Wang, J., Wolf, R. M., Wu, X., Xiao, L., and Kollman, P. A. (2018) AMBER 2018; University of California, San Francisco, CA.

(56) Morris, G. M., Huey, R., Lindstrom, W., Sanner, M. F., Belew, R. K., Goodsell, D. S., and Olson, A. J. (2009) Software News and Updates AutoDock4 and AutoDockTools4: Automated Docking with Selective Receptor Flexibility. J. Comput. Chem. 30, 2785.

(57) O'Boyle, N. M., Banck, M., James, C. A., Morley, C., Vandermeersch, T., and Hutchison, G. R. (2011) Open Babel: An Open Chemical Toolbox. J. Cheminf. 3, 33.

(58) Humphrey, W., Dalke, A., and Schulten, K. (1996) VMD: Visual Molecular Dynamics. J. Mol. Graphics 14, 33.

(59) Bagdasarian, M., Lurz, R., Ruckert, B., Franklin, F. C., Bagdasarian, M. M., Frey, J., and Timmis, K. N. (1981) SpecificPurpose Plasmid Cloning Vectors. II. Broad Host Range, High Copy Number, RSF1010-Derived Vectors, and a Host-Vector System for Gene Cloning in Pseudomonas. Gene 16 (1-3), 237-247. 